\title{
THE FLOOR STIFFNESS EFFECT ON VULNERABILITY ASSESSMENTS AND INTERVENTION DESIGNS OF HISTORIC BUILDINGS: THE CASE STUDY OF THE "PROCURATIE VECCHIE" IN VENICE, ITALY
}

\author{
IRENE ROCCA $^{1}$ *, LUISA BERTO ${ }^{1}$, SONIA BELLIN ${ }^{2}$, BEAUDIN F. DONGMO $^{3}$, \\ ANNA SAETTA ${ }^{1}$, RENATO VITALIANI ${ }^{4}$ \\ ${ }^{1}$ DCP - University IUAV of Venice \\ Campus Terese, Dorsoduro 2206- 30123 Venice - Italy \\ e-mail: irocca@iuav.it; lberto@iuav.it; saetta@iuav.it \\ ${ }^{2}$ Structural engineer \\ e-mail: soniabellin93@gmail.com \\ ${ }^{3}$ Structural engineer \\ e-mail: fdongmo@yahoo.fr \\ ${ }^{4}$ DICEA - University of Padua, \\ Via Francesco Marzolo 9, 35131 Padova - Italy \\ e-mail: renato.vitaliani@unipd.it
}

Keywords: Historical Structure, Masonry, Floor in-plane stiffness

\begin{abstract}
In the Italian seismic scenario, and beyond, interventions on existing buildings focused on the evaluation and reduction of seismic risk of cultural heritage have gained more and more importance in the engineering field.

Therefore, for the designer it becomes increasingly useful to have a methodology that allows to carry out, in the study of an existing structure behavior, the vulnerability assessment of both the actual state and the design state, evaluating the adequacy of potential intervention of seismic improvement.

In this paper some phases of this methodology are presented in the context of the restoration work started in November 2017, and currently in progress, of the historical building of Procuratie Vecchie in Piazza San Marco in Venice, with particular focus on the consolidation intervention of the timber floors which satisfy the conservation requirements imposed by the Superintendence of Venice. Actually, the influence of floor diaphragms on structural behavior of existing masonry building subjected to seismic action is critically discussed with particular reference to the effects of in-plane stiffness of floors on the seismic distribution of forces on lateral walls and on the out-of-plane mechanism of the walls.
\end{abstract}




\section{INTRODUCTION}

The damage caused by recent and past earthquakes in Italy and in the Mediterranean area has shown the high seismic vulnerability of the cultural heritage. Therefore it is mandatory to invest in interventions on historical constructions, aimed to the reduction of their seismic risk. In this field, one relevant case study is represented by the restoration work currently in progress in the Procuratie Vecchie in Piazza San Marco in Venice.

Some aspects of this work are described in the present paper, focusing to the timber floors consolidation intervention and its effect on the seismic response of the building. Starting from the design restrictions of complete reversibility of the intervention and low degree of invasiveness on the historic building, an effective and non-invasive solution was proposed for the consolidation of timber floors based on the insertion of steel ring beam (i.e. a steel perimeter chord) and a doubly diagonal mesh of flat steel ties anchored to the beams and to the perimeter walls. The proposed intervention guarantees proper resistance and stiffness to the floor, without significant modifications of the global dynamic behavior of the structure.

It is worth noting that this type of floor does not behave as an infinitely rigid diaphragm, and this consolidation intervention can be considered classifiable as limited stiffening. In order to study the relation between floor stiffness and the earthquake resistant structures behavior (i.e. the masonry walls), and to establish the proper interventions, the results of four different models of a portion of Procuratie Vecchie are critically discussed. The selected portion of the building is representative of a "module" between two subsequent masonry wall

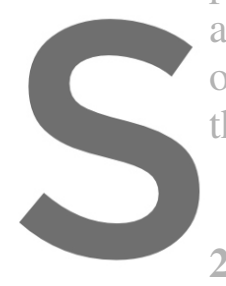
alignments. The four models simulate four
order to capture the progressive effect of increa
the various structural components.

2 THE "PROCURATIE VICCHIE" IN VENCE: RNOW
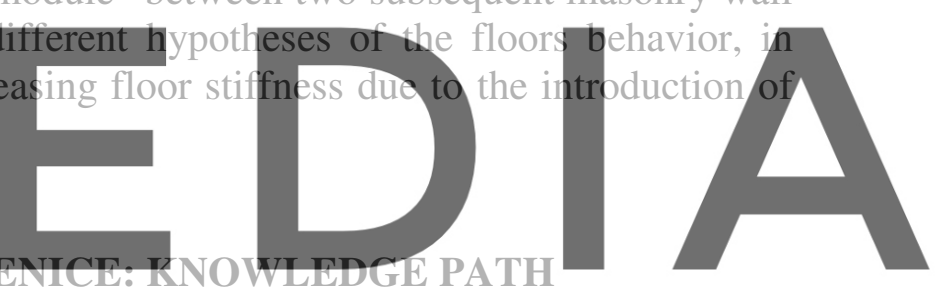

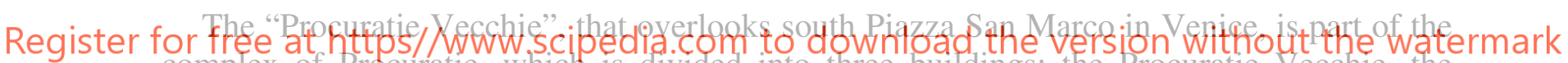
complex of Procuratie, which is divided into three buildings: the Procuratie Vecchie, the Procuratie Nuove, dating back to the 14th century, and the Procuratie Nuovissime, or Ala Napoleonica, built by Napoleone Bonaparte in the early 19th century (Figure 1 and Figure 2).

The Procuratie Vecchie building was erected in the $12^{\text {th }}$ century, at will of Doge Sebastiano Ziani in order to host the accommodation of the Procurators of Venice. There is no evidence of the original internal distribution, due to the scarcity of sources related to the building in medieval times.

After the destruction caused by fire on February $1^{\text {st }} 1512$, great reconstruction works took place, which were well documented through iconography, even if the actual design authorship of the reconstruction work is not completely certain. There is certainty that between 1519 and 1529 the Procuratie Vecchie construction site was directed by Bartolomeo Bon (at least for the Clock Tower up to the Sottoportico dei Dai), while from the Sottoportico dei Dai to the San Geminiano Church the project is certainly attributable to Jacopo Sansovino. Later in 1909, the substantial restoration of the building, especially in terms of internal distribution, was entrusted to engineer Fano. He made substantial modifications to the building, especially in terms of internal distribution, as the new client's intention was to transform the traditional residential function maintained by the Procuratie Vecchie up to that time into office functions. 

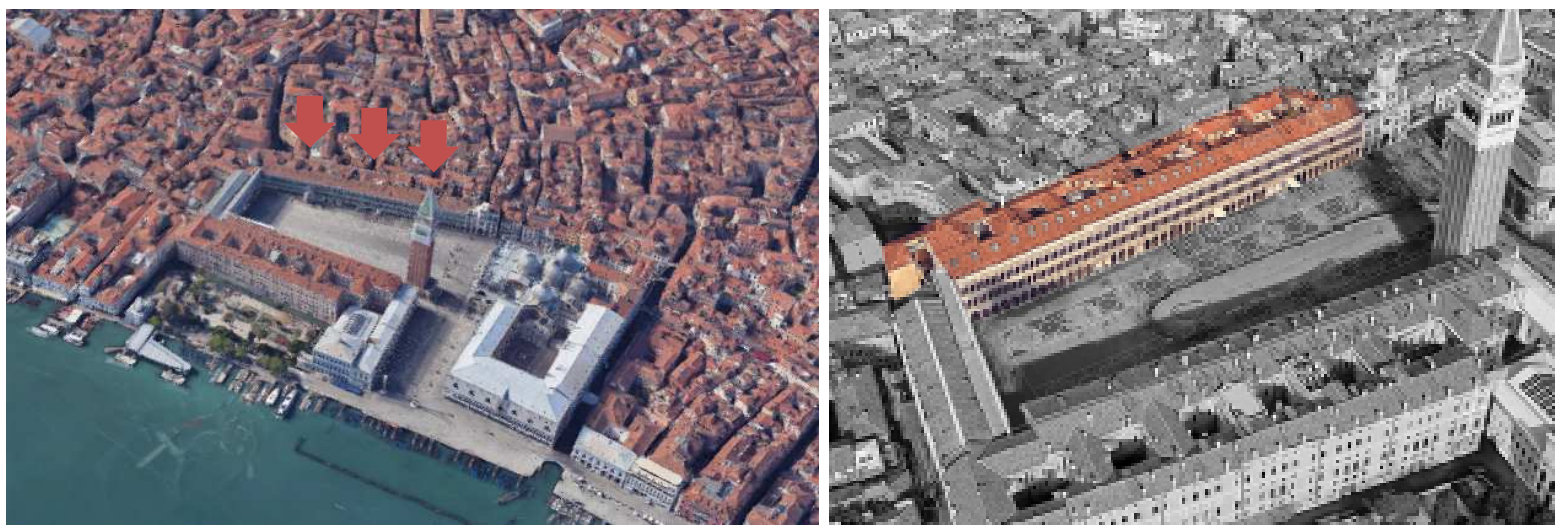

Figure 1: Indication of Procuratie Vecchie in the: (a) Aereal view of Piazza San Marco; (b) Procuratie complex
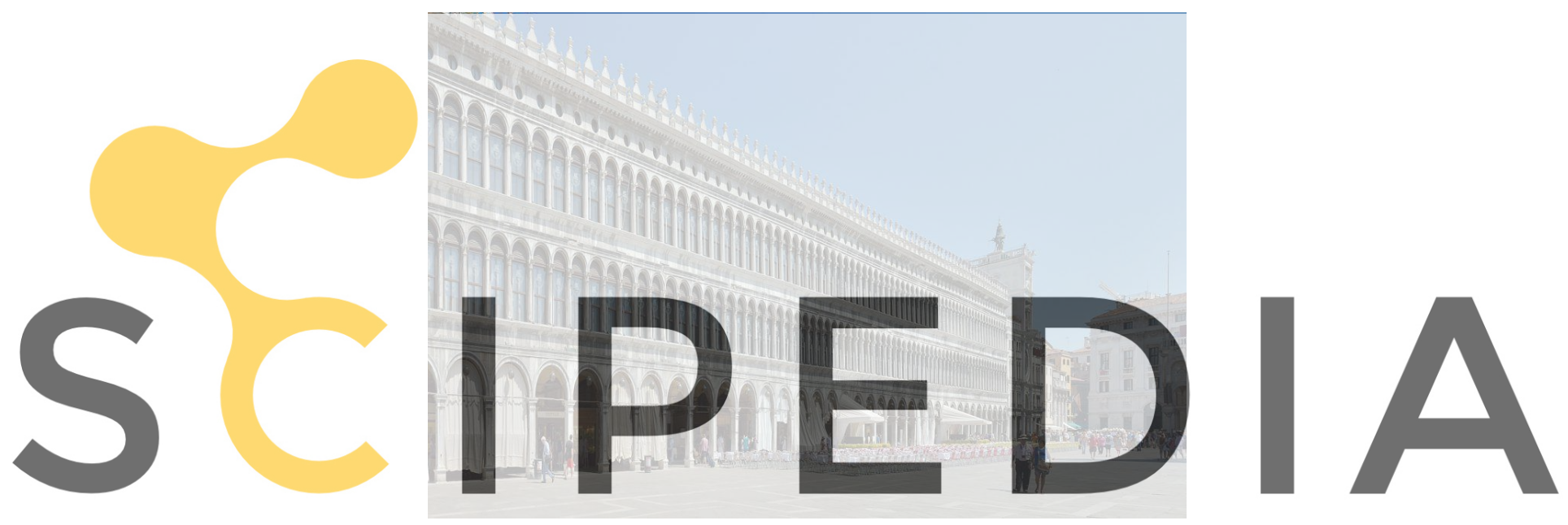

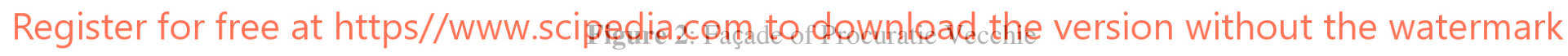

The Procuratie Vecchie have a load-bearing brick masonry structure with a roughly rectangular and rather elongated shape, with a greater side of $152 \mathrm{~m}$ oriented along the EastWest axis and a smaller side of $25 \mathrm{~m}$ along the North-South axis. The building has eight storeys above ground (four noble storeys, three mezzanine storeys and an attic storey), all characterized by the same overall plan extension, except for the attic.

Regarding the inter-storey height, the floor of the mezzanine level, originally placed over the entire storey plan extension, were largely demolished during the restoration works that affected the building in the twentieth century, increasing the inter-storey height in such positions. The building has a top height of $21.4 \mathrm{~m}$ in the western part (for the whole extension of the attic storey), and a lower height of $19.0 \mathrm{~m}$ at the top for the remaining portion. The monumental façade on San Marco Square is $16.7 \mathrm{~m}$ high and is entirely made of white Istrian stone.

All the information about the dimensions and geometry of the entire Procuratie Vecchie building in its actual state was provided by the geometric survey, carried out with an integrated methodology of direct-and-instrumental survey. 
Then an accurate material-constructive survey was carried out in order to acquire knowledge about the materials and their state of conservation, as well as the technique used to construct the building, the relationships between the parts, and the quality of the building itself (e.g. the accordance with the best constructive practices, the so called "rules of thumb"). To this aim, many visual inspections were carried out together with a limited number of weakly destructive tests for the material characterization (e.g. for masonry: single and double flat jacks tests, Shove test, petrographic characterization of mortar) according to Italian Regulation D.P.C.M. 9/02/2011 [1] and Commentary of Italian Technical Standards NTC08 (2009) [2] in order to obtain a knowledge level equal to LC2 (which corresponds to KL2, Normal Knowledge in Eurocode 8-part 3 [3]).

The masonry of vertical elements was classified as solid brick masonry with lime or cement-lime mortar joints with regular texture. The only exception is represented by the façade facing Piazza San Marco that, as previously stated, is made of white Istrian stone.

The orthogonal walls are well connected, while, with regard to the connection between walls and floors, several critical points were highlighted, requiring restoration interventions.

Besides, seventy visual inspections were carried out for characterizing the floor system. Two prevalent floor types have been identified:

1. one-way timber floor with beams and simple plank;

2. one-way hollow bricks and concrete floor with joists cast on site

For both of them different variants are present in terms of layers' thickness, geometrical

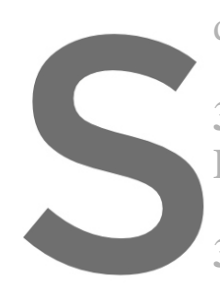
dimension, spacing of timber

3 OVERVIEW OF THE ENTIRE BUILDING

3.1 Seismic action
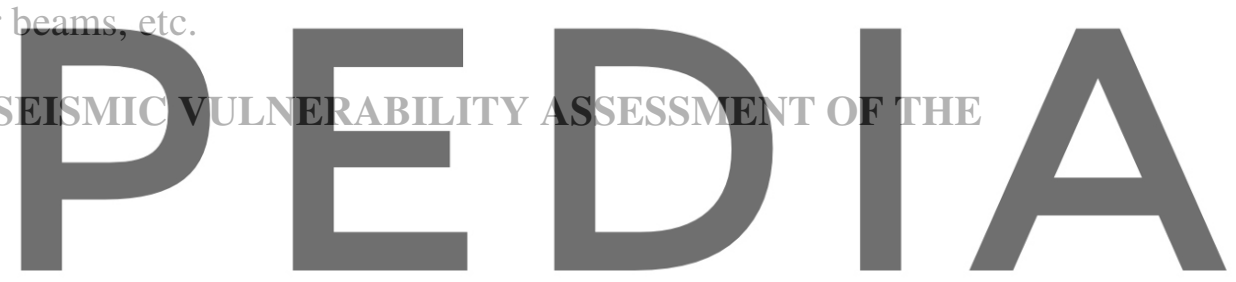

The seismic action has been assessed according to NTC2018 [4] and the probabilistic

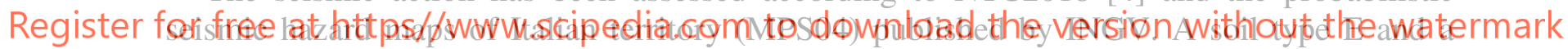
topographic category T1 were assumed. For the building, a reference period $V_{R}$ equal to 75 years was assumed, which corresponds to a return period $T_{R}$ of the seismic action at LifeSafety Limit State equal to 712 years, with a PGA value equal to $0.128 \mathrm{~g}$. A behavior factor $q$ equal to 2.25 was adopted.

\subsection{Seismic analyses}

Historic masonry buildings, like Procuratie Vecchie, are complex for their typology and construction techniques. Therefore the analysis of their structural behaviour and their seismic assessment are conditioned by significant uncertainties in defining the mechanical properties of the materials and the connection conditions of the various elements, which can make the results of the numerical analysis on the whole building not reliable enough. In particular, the activation of local collapse mechanisms does not allow the structure to behave as a whole, and then these activations have to be checked.

Firstly, preliminary evaluations of seismic safety were performed according to the Evaluation Level 1 (LV1) introduced in [1], by means of the simplified mechanical model defined for "Buildings, villas and other structures with bearing walls and horizontal 
diaphragms".

Then local collapse mechanisms of single portions of the building were evaluated according to the Evaluation Level 2 (LV2), that is based on the evaluation of individual macro elements. Among others, the simple overturning of the façade facing San Marco's Square, the overturning of the corner on San Marco's Square and the horizontal confined wall deflection on the Bacino Orseolo side are analyzed.

Then, starting from the information collected by the geometric and material constructive survey of the building, a global FE model of the building was created in order to study its dynamic behavior, Figure 3. The numerical analyses were performed with the FE program Midas Gen [5]. The types of element used are:

- 3 or 4 node Shell elements, with both flexural and membranal stiffness, for the walls;

- Truss elements for the columns of the porticoes and the columns of the arches characterizing the facade of San Marco's Square, as well as for the tie rods at the various floors:

- Beam elements for the floor beams. It is worth noting that, in this global model, the timber floors are modelled with equivalent beams which guarantee the same stiffness of the actual timber floor.
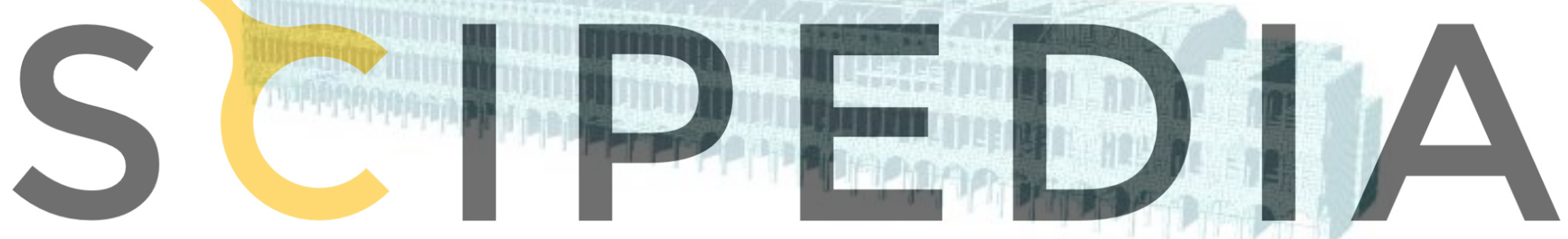

Register for free at https//www.scipedia.com to download the version without the watermark Figure 3: Global FEM of Procuratie Vecchie building in Piazza San Marco, Venice. (Midas Gen)

The model of the structure has been fixed at the base and the interaction with the adjacent buildings has been neglected considering also that they were constructed in successive periods. All the details about geometrical characteristics, material properties and acting loads can be found in [6].

Masonry has been modelled as isotropic linear elastic material. Lateral force method of analysis and modal response spectrum analysis were carried out. The choice to perform linear elastic analysis is mainly motivated by the scarcity of available data on the materials, due to the conservation restrictions imposed by Superintendence and by the private ownerships, which did not allowed to reach a knowledge level sufficient to carry out reliable non-linear analyses. Secondly, the linear analysis allows to have a reasonable description of the process leading to a possible crack pattern and to maintain a good control on the results.

\subsection{Vulnerabilities and consolidation interventions}

The static and seismic verifications carried out on wall alignments have identified some 
vulnerabilities, which can be solved with consolidation interventions of the masonry structure, elimination of the local mechanisms of collapse and consolidation of timber floors, both from the point of view of stiffness and resistance. This last intervention improves the floor behavior making the floor capable of resisting the greater imposed load due to the change in functional destination of the building and at the same time of transferring the seismic actions to masonry bracing walls and of limiting the out of plane deformation of the walls.

Focusing on the timber floor intervention, in order to comply with both structural safety issues and conservation requirements (e.g. complete reversibility and low degree of invasiveness on the existing building), an effective and non-invasive solution has been proposed for the consolidation of timber floors. It consists of reuse of the main existing timber beams; replacement of the existing timber floor with a new one, with improved mechanical characteristics ( $3 \mathrm{~cm}$ thick); insertion of steel ring beam (i.e. a steel perimeter chord) with an L-shaped section $75 \times 75 \times 8$, connected to masonry walls by proper anchors; insertion of a doubly diagonal layer of steel band (width $80 \mathrm{~mm}$ and thickness $1.5 \mathrm{~mm}$ ) anchored to the beams and to the perimeter walls, as well as to the timber floor by means of mechanical nail connectors, in order to guarantee an overall floor diaphragm behavior (Figure 4).
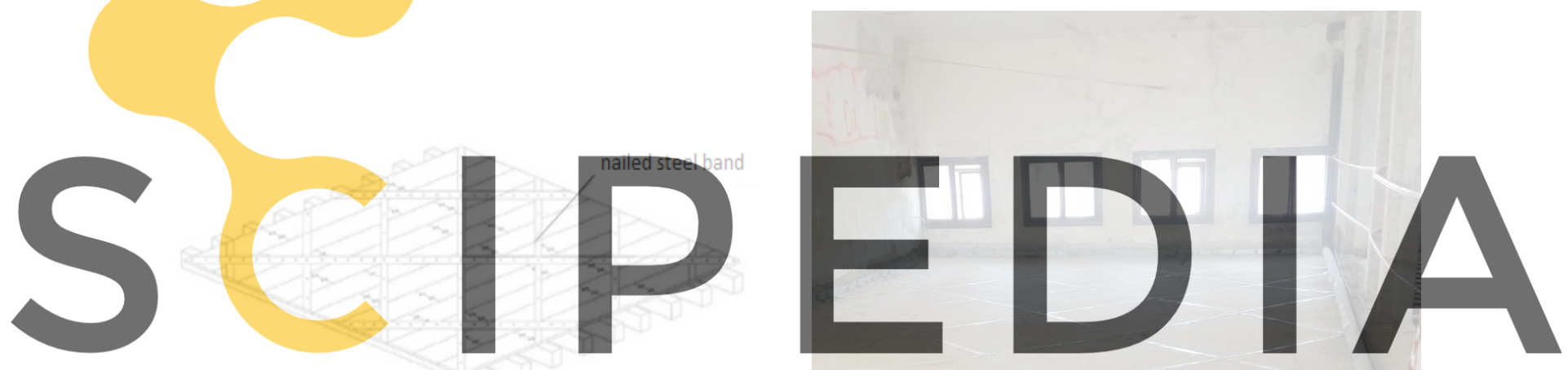

\section{Register for free at https//www.scipedia.com to download the version(wyithout the watermark}

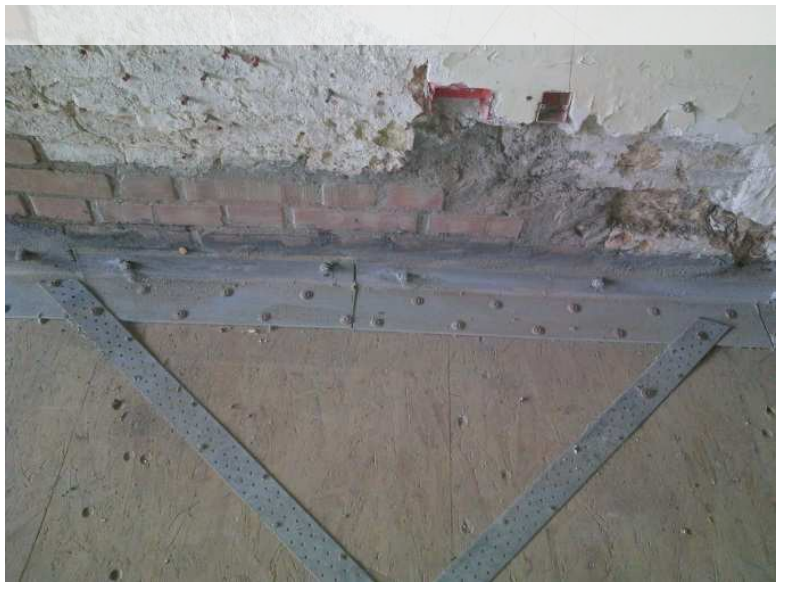

(c)

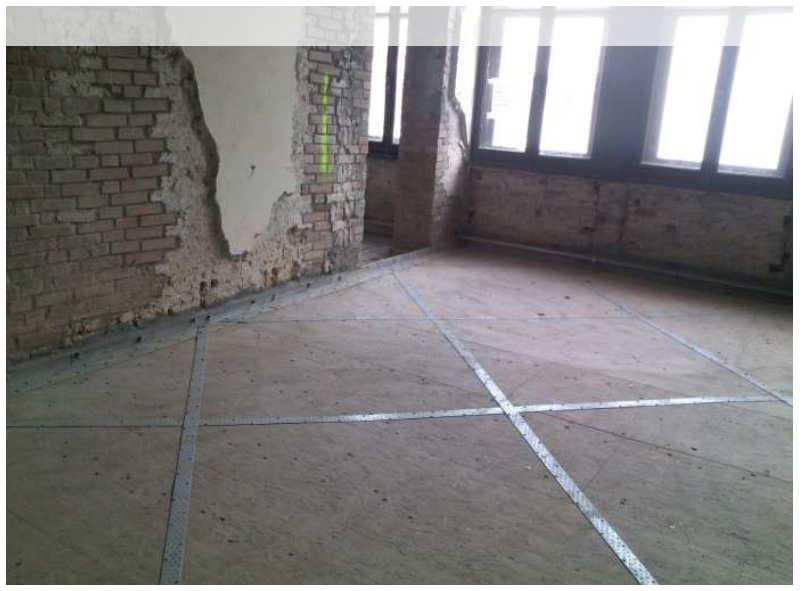

(d)

Figure 4: Reinforcement intervention of timber floors: (a) schematic representation; (b)-(c)-(d) views of the intervention. 
This kind of intervention is simple and has the advantages of the dry strengthening techniques. It ensures an improvement of wooden floor behavior, increasing its strength and in-plane stiffness minimizing the additional load on the existing structure and without significantly modifying the structural dynamic behavior. In the following, it is shown that this type of floor does not behave like an infinitely rigid diaphragm, instead it can be classified as a "limited stiffening" (see Commentary of NTC 2018 [7]). This type of reinforcing intervention has been successfully adopted in the restoration works on the 'La Fenice' Theatre in Venice, described in [8], destroyed by fire in 1996. Since then it has been used in many other cases for the restoration of monumental building floors.

\section{THE ROLE OF IN-PLANE FLOOR STIFFNESS IN THE SEISMIC BEHAVIOUR OF THE BUILDING}

\subsection{Sub-structure FE models}

In order to study the influence of floor diaphragms on structural behavior and the effects of floor stiffness, a portion of the Procuratie Vecchie - with plan dimensions about $6.2 \times 24.0 \mathrm{~m}$ between two subsequent masonry wall alignments is considered. Therefore, the model represented in Figure 5 was analysed considering different hypotheses for floor models characterized by increasing stiffness.
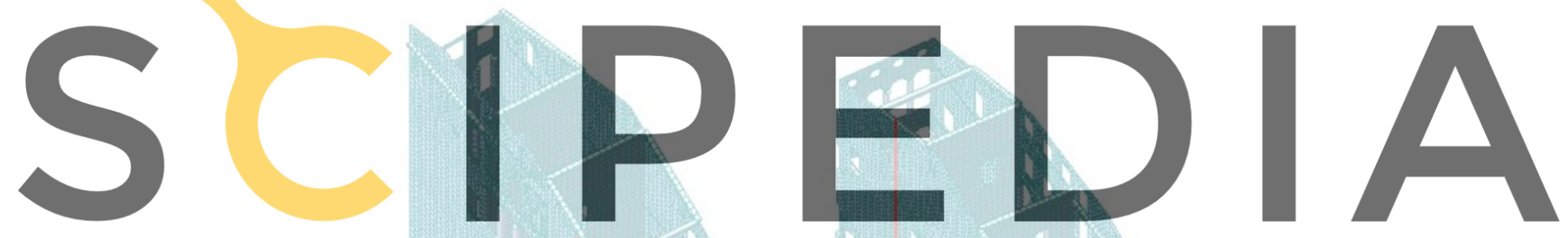

Register for free at https//www.scipedia.com to download the version without the watermark
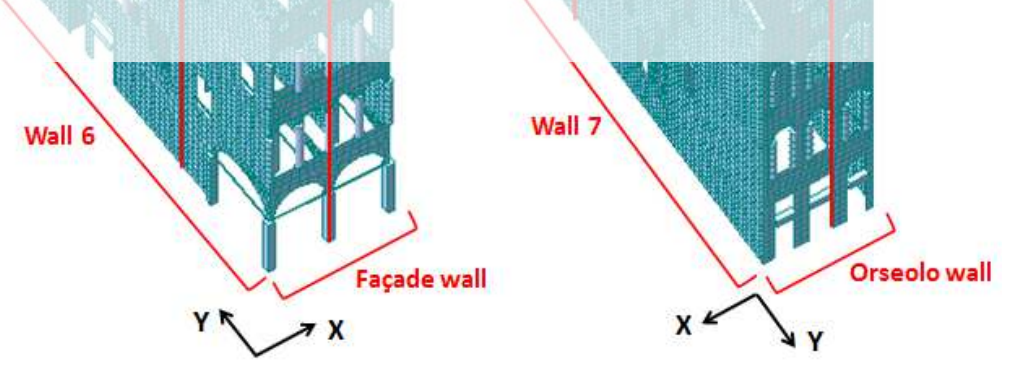

Figure 5: Sub-structure FE model with identification of the wall alignments considered

Masonry walls, columns and all the other structural elements were modelled as in the global model described in $\$ 3$ and the building was assumed fixed at the base and the walls perfectly connected to each other. Regarding floor modelling, four different models are considered in order to capture the progressive effect of increasing floor stiffness:

- Model 1: floors modelled only with beam elements of rectangular section with spacing 38

$\mathrm{cm}$ (simulating the actual timber beams $-15 \times 20 \mathrm{~cm}$ ). 
- Model 2: representative of the actual condition. Floors modelled with beam elements and 4-nodes plate elements, $3 \mathrm{~cm}$ thick, respectively representing the timber beams and the over placed timber plank. These 1D and 2D elements were connected by elastic springs of lateral translational stiffness estimated considering Eurocode 5 [9] formula for the case of nailed connection. This Standard provides a value of stiffness for each single connection element $K_{\text {ser }}$ (instantaneous sliding module), that for timber-timber joints and for nail with pre-drilling connector in absence of more accurate determinations can be assumed as:

$$
K_{\text {ser }}=\rho_{k}^{1.5} \frac{d}{20}\left[\frac{\mathrm{N}}{\mathrm{mm}}\right]
$$

where $d$ represents the nail diameter in $m m$ and $\rho_{k}$ the characteristic value of timber density expressed in $\mathrm{kg} / \mathrm{m}^{3}$.

- Model 3: representative of the proposed intervention. The floor model is obtained starting from the actual state model (i.e. Model 2), in addition using beam elements with Lsection all around the walls, connected through Rigid Links to the masonry elements (supposing rigid connection), and truss elements of Tension Only type, to model the doubly diagonal steel band on the surface of the timber floors. These strips are linked in continuity with the Beam elements, while to the underlying plank with Rigid Links.

Model 4: (limit condition) floors modelled with the conventional schematization of in plane infinitely rigid diaphragm, often used in the professional practice. It is realized by a

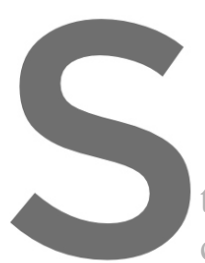
Master Node (i.e. masonry elements

In Models 1-2-3 the to the masonry nodes case of seismic action.
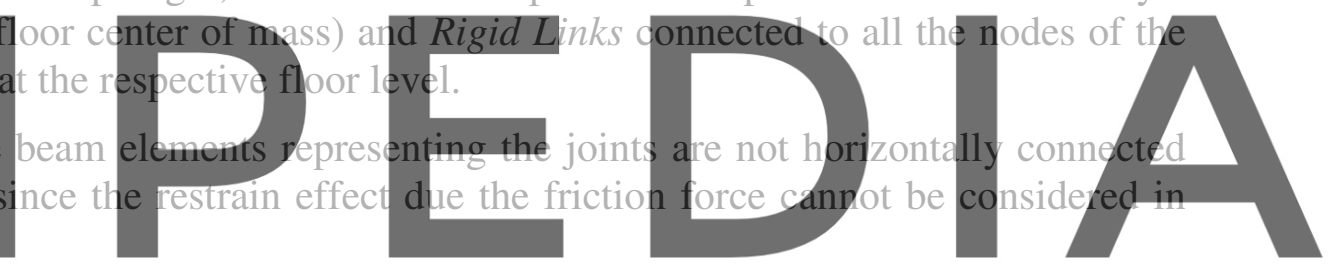

The seismic action was applied as nodal forces acting at masonry at the floor level. The

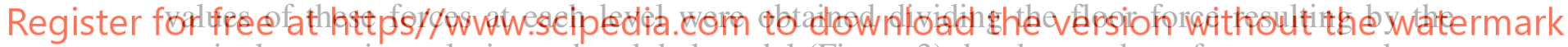
equivalent static analysis on the global model (Figure 3), by the number of masonry nodes at the related level since the inertial force is primarily due to the mass of the walls, which are much heavier than the floors. The magnitude of floor force applied at each level is equal for all the four models. The permanent and accidental loads were applied in the models as summarized in Table 1. 
Table 1: Different floor models considered in the study

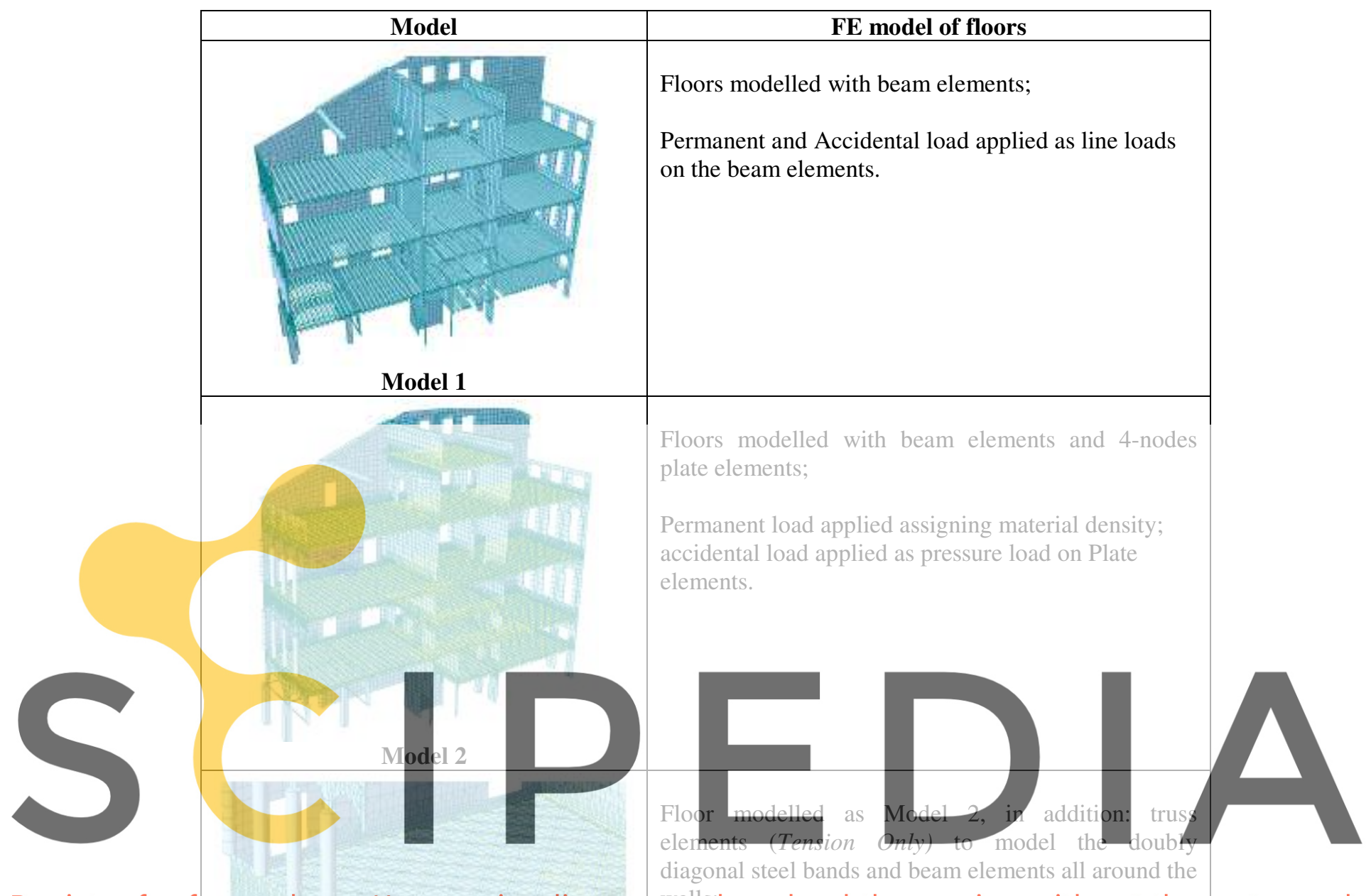

Register for free at https//www.scipedia.com todl download the version without the watermark

\begin{tabular}{|c|l|}
\hline Model 3 & Permanent and Accidental load applied as in Model 2. \\
\hline & Rigid floor (master/slave); \\
& $\begin{array}{l}\text { Permanent and accidental loads applied as Floor Load } \\
\text { in the area where the floors are present. }\end{array}$ \\
\hline Model 4 & \\
\hline
\end{tabular}




\subsection{Floor stiffness effect on vulnerability assessments}

In order to evaluate the effect of in-plane stiffness of floors on the seismic distribution of forces on lateral walls and on the out-of-plane mechanism of the walls, the horizontal displacements obtained by the numerical analyses for seismic actions acting alternately in $\mathrm{X}$ and Y plan directions are considered.

In Figure 6 and Figure 7, for example, the profiles of the horizontal displacement obtained for action in $\mathrm{X}$ direction are reported in correspondence of the four vertical sections of the walls, identified in Figure 5, in order to investigate the in-plane and out-of-plane behaviour of the walls, respectively for Façade and Orseolo walls and for 6 and 7 walls.

As observable, the displacement decreases significantly with the increase of the floor inplane stiffness. The Façade wall in Model 1 (which substantially corresponds to the absence of floor diaphragm action) shows a very high horizontal displacement, with a high drift at the 1 st level (height 2.6m) due to the presence of pillars at ground floor (Figure 5). In design conditions (Model 3) these displacements decrease a lot, remaining nonetheless greater than those obtained with Model 4 (which corresponds to the case of infinitely rigid floor). Orseolo wall (which is an almost full masonry from ground to roof), due to its higher horizontal stiffness, shows a horizontal displacement in the actual condition (Model 2) equal to about one third of the corresponding value on the Façade. On the other hand the design condition (Model 3) ensures greater homogeneity of displacements between the different walls, including the façade wall, greatly reducing the maximum displacement values (both in-plane

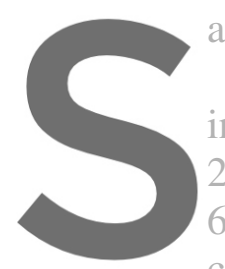
and out-of-plane) without reaching the case of the infinitely rigid floor model. The effect of seismic
intervention are apprecia
2 ) in terms of displacem
6 and 7 ). In particular,
corresponds to about $68 \%$ (1) P $E D \mid A$ and 7 .

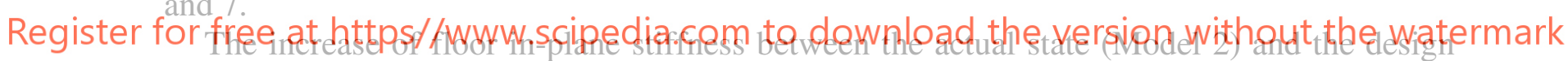
state (Model 3) for both X and Y directions can be observed from Figure 8, where, for each level, the ratio between the maximum horizontal displacement of the floor and the corresponding one in case of rigid diaphragm assumption (Model 4) is displayed. In design state (Model 3), the maximum displacement settles at values that are approximately double the one of rigid floor hypothesis (Model 4), for both seismic forces directions. The effect of floor consolidation intervention (i.e. from actual state to design state) is more felt in $\mathrm{X}$ direction than in $\mathrm{Y}$ direction since the presence of multiple walls in this direction makes the hyperstatic force distribution more affected by the diaphragm in-plane stiffness. 


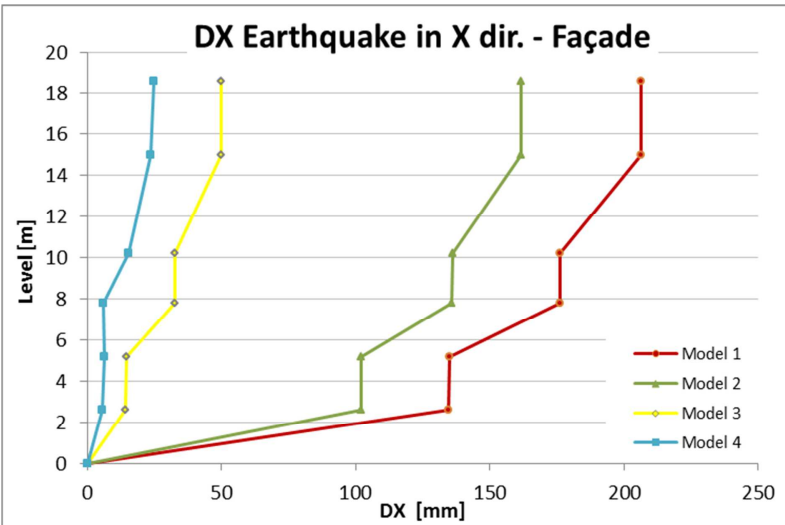

(a)

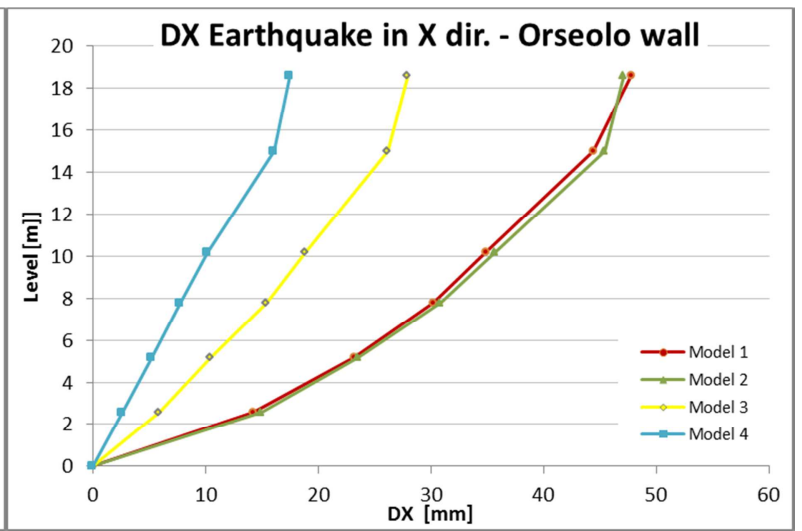

(b)

Figure 6: Seismic action along X direction: in-plane effect. DX displacements profile along the height in correspondence of the middle vertical section for: (a) Façade wall; (b) Orseolo wall

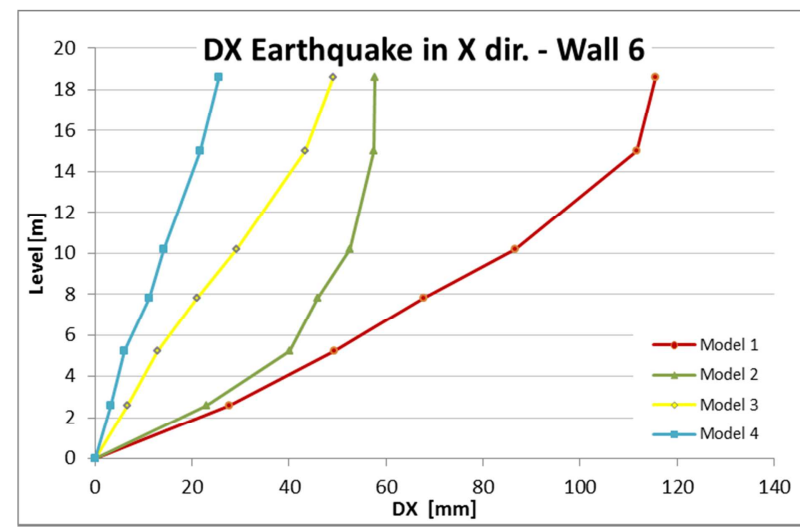

(a)

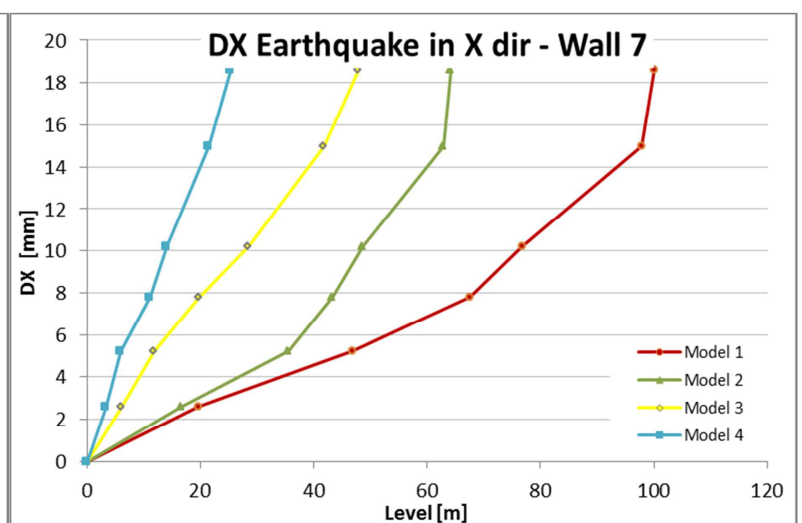

(b)

Figure 7: Seismic action along X direction: out-of-plane effect. DX displacements profile along the height in correspondence of the vertical section South for: (a) Wall 6; (b) Wall 7

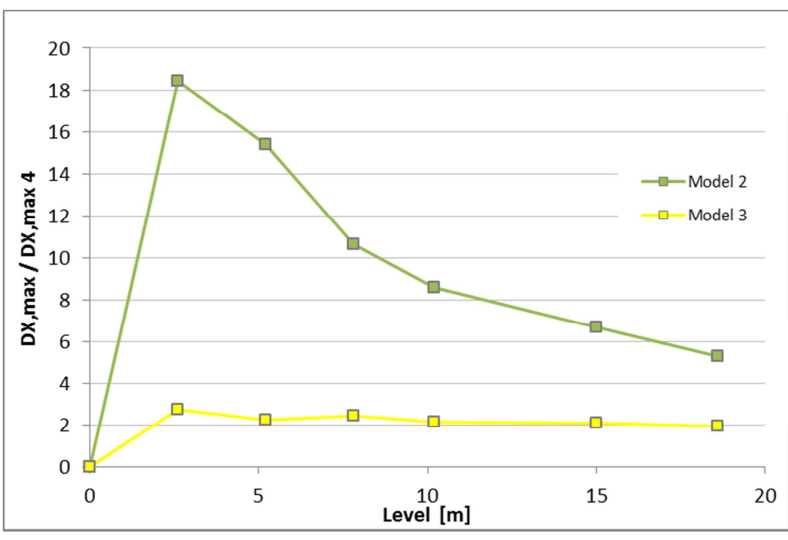

(a)

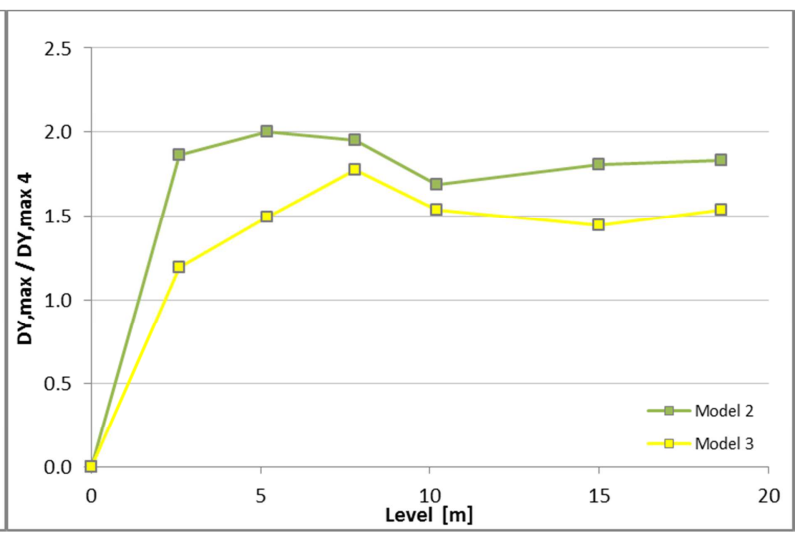

(b)

Figure 8: Ratio between the maximum horizontal displacement of the floor and the corresponding one in case of rigid diaphragm assumption: (a) Displacements in $\mathrm{X}$ direction for seismic input in $\mathrm{X}$ direction, (b)

Displacements in $\mathrm{Y}$ direction for seismic input in $\mathrm{Y}$ direction 


\section{CONCLUSIONS}

The proposed case study, the Procuratie Vecchie in Piazza San Marco in Venice, is an example of historical buildings that can be highly vulnerable to seismic actions if in-plane strength and stiffness of floors are not enough to limit out-of-plane mechanisms of walls and to distribute effectively the seismic forces among lateral walls.

The proposed consolidation intervention for the timber floors is investigated and compared to the actual condition and to the infinitely rigid diaphragm case. It is demonstrated that the proposed consolidation intervention can be considered as of "limited stiffening", being able to increase the strength and stiffness of the traditional flexible floor, but not so much to make it an infinitely rigid diaphragm. In this way the building behaviour is improved, allowing the redistribution of horizontal forces and preventing the collapse of the most vulnerable walls. Moreover, the design restrictions of complete reversibility of the intervention and low degree of invasiveness are also respected, necessary in a building belonging to the national historical and cultural heritage.

\section{REFERENCES}

[1] DPCM 2011: Direttiva P.C.M. 12 ottobre 2007 per la valutazione e riduzione del rischio sismico del patrimonio culturale tutelato, S.O. n. 25 alla G.U. n. 24 del 29 gennaio 2008, update 9 febbraio 2011, (GU n. 47 del 26.02.11), (in Italian)

[2] CSLLPP. Circolare 02 febbraio 2009 n. 617 Istruzioni per l'applicazione delle "Nuove norme tecniche per le costruzioni" di cui al DM 14 gennaio 2008. Gazzetta Ufficiale della Repubblica Italiana n. 47, Supplemento Ordinario n. 27. (In Italian)

[3] EC8: EN 1998-3:2005 Eurocode 8: Design of structures for earthquake resistance. Part 3Assessment and retrofitting of buildings

[4] MIT - Ministro delle infrastrutture e dei trasporti, G.U. S.O. n 42, 20 February 2018. NTC (2018) Aggiornamento delle «Norme tecniche per le costruzioni», decree on 17 January 2008; 2018. (in Italian)

[5] Midas Gen 2020 User's guide, getting started \& tutorials

[6] Bellin, S. Il caso studio delle Procuratie Vecchie di Venezia: un esempio di recupero di un bene architettonico vincolato con valutazioni sulla rigidezza di piano, Master Thesis, University of Padova, Civil, Environmental and Architectural Engineering Department, Academic year 2017-2018

[7] MIT - Ministro delle infrastrutture e dei trasporti Circ. C.S.Ll. 21 gennaio 2019 n. 7. Istruzioni per l'applicazione dell'«Aggiornamento delle "Norme tecniche per le costruzioni” 》 di cui al decreto ministeriale 17 gennaio 2018; 2019. (in Italian)

[8] Gasparini, A., Serafini, G., Scotta, R., Vitaliani, R., Saetta, A. Retrofitting of 'La Fenice' Theatre for Seismic Loads. ConMat'05 3rd Int. Conf. on Construction Materials: Performance, Innovations and Structural Implications, Vancouver, Canada, August 22-24, 2005

[9] EN 1995-1-1:2004 (2004) Eurocode 5: Design of timber structures - Part 1-1: General Common rules and rules for buildings 